Gloria Kirwan, Conor Mc Guckin:

\title{
Professional Reputation and Identity in the Online World
}

\begin{abstract}
:
The interface between new entrants to professional disciplines, professional reputation management and social media usage is an under-researched and little understood phenomenon. A small-scale study on social media usage conducted with new social workers and teachers, working in the Irish context, revealed interesting insights into the complexities of reputation management for new professionals and the particular issues related to development of their professional reputations raised by online interactions, relationships and behaviour. Key messages for professionals and professional educators emerge from the findings outlined in this article.
\end{abstract}

\section{Agenda:}

Introduction

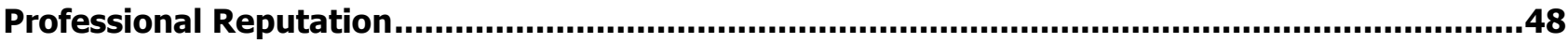

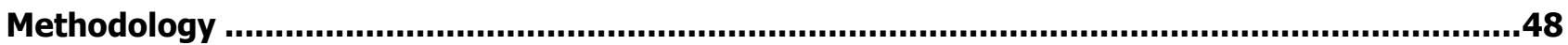

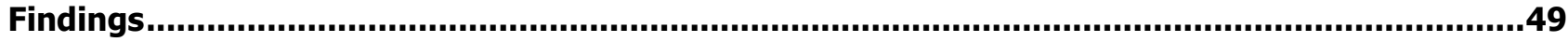

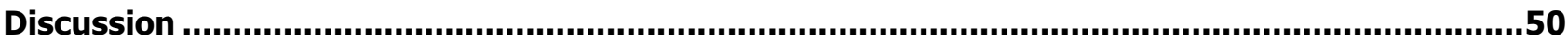

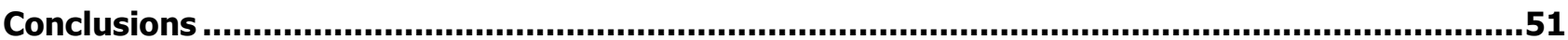

\section{Authors:}

Gloria Kirwan:

- School of Social Work and Social Policy, Arts Building, Trinity College Dublin, Dublin 2, Ireland.

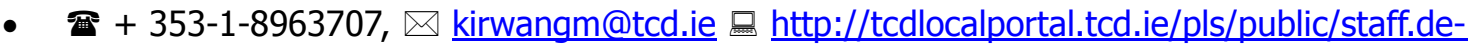
tail?p unit $=$ swsp\&p name $=$ kirwangm

- Relevant publications:

- Social media, e-professionalism and netiquette in social work, Irish Social Worker, Autumn (2012): 9-12.

Conor Mc Guckin

- School of Education, Trinity College Dublin, Dublin 2, Ireland.

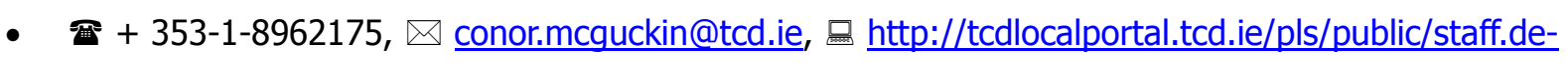
tail?p unit=education \&p name $=$ mcguckic

- Relevant publications:

- Using Google Analytics to Evaluate the Impact of the CyberTraining Project., Cyberpsychology, behavior and social networking 15, No.11 (2012): 625 - 629. 


\section{Introduction}

This paper draws on data generated from a previous study in Ireland on social media usage, conducted with newly qualified teachers and social workers, which explored the issue of professional relationships and relationship boundaries in asynchronous social media environments. This article revisits the interviews from that study to mine the data to see what they reveal on the issue of professional reputation in the context of online social interactions.

\section{Professional Reputation}

In the professional context, reputation is strongly linked with the professional identity and character which new professional graduates, across various disciplines, construct for themselves and transport into their work environment. Closely associated with the concept of integrity, the foundation of a good professional reputation is built on "honesty, trustworthiness and personal character" (Cournoyer, 2008:24). Professional reputation relies on the demonstration of "high standards of professionalism" (Cournoyer, 2008:24) as well as behaviour, in general, that is consistent with responsible conduct that "adheres to social norms and values" (Eisenegger, 2009:11). As Eisenegger (2009:13) further points out, reputation is more than functional competence, it has a moral dimension. One can improve on performance of a role or a task by developing skills and knowledge, but it is difficult to recover from a moral lapse, particularly if that is associated with one's role performance. Therefore, reputation in the professional world is linked inextricably to one's perceived moral compass and anything, particularly overt behaviour on or off the job, which casts that in any doubt, may damage reputation, sometimes irreversibly. Where reputation is weak or lost, lack of public confidence in professional services can easily follow, as has been highlighted by negative public reactions to media revelations of poor performance (for discussion of the issue of confidence in a professional context see Wilson, Ruch, Lymbery and Cooper, 2011:48). Maintaining professional reputation, at an individual and profession-wide level, it seems, is a foundational cornerstone on which service delivery depends.

In the cyberworld, however, many potential pitfalls exist related to the types of information that people may share online (sometimes unwittingly). As a consequence, new professionals can quickly find their digital footprint or current online behaviour serves not to enhance but to compromise that very nascent reputation which they are seeking to establish within their chosen profession. Damage to professional reputation or engaging in behaviour (on- or off-line) which is incompatible with the newly acquired professional identity, can quickly interfere and possibly compromise the transition of a new graduate into the professional role.

Through our research on usage of asynchronous technologies, conducted with newly qualified teachers and social workers, it has been possible to gain insight into self-reported online behaviour, including the types or forms of online personae which participants adopt as well as features of their online bio-histories which participants reported on in the course of a set of focus group interviews. While the data collected over the course of the study cover a wide diversity of issues, this article focuses on what they reveal about the interface between social media relationships and professional reputation.

\section{Methodology}

Through the medium of focus group interviews (Krueger \& Casey, 2009), groups of recent graduates drawn from two professions, teaching and social work, were asked to discuss the extent of their engagement (current and historical) on social media and how they experienced interaction on asynchronous media, in the postgraduation, early employment phase of their careers. 
The focus group moderators facilitated discussion with the use of a pre-defined set of guide questions but also allowed free-flowing commentary into new topics throughout the interviews. The groups were recorded, transcribed and thematically analysed.

The focus group interviews scoped a wide range of issues related to social media usage among the participants. During the course of one focus group in particular, a lengthy dialogue took place between the participants on the issue of professional reputation and social media usage. The findings reported here draw heavily from the data contained within that particular focus group interview, which was conducted with a group of people who were employed as social workers in different settings and who had commenced their careers in Ireland as social workers within the last five years.

The interviews explored with participants their practices, views and experiences of asynchronous technologies (including Facebook, Blogs, Twitter, Podcasts, Wikis, YouTube and Tumblr) and how this overlaps, supports, compromises or conflicts with their newly acquired professional identity. From the collected data, information emerges regarding how the study participants conceptualised their online personae in terms of their overlap with their newly acquired professional identities. The findings discussed in this article reveal the viewpoints held by participants regarding the interaction between their online personae and the professional domain into which they are transitioning.

\section{Findings}

The focus group from which the data are drawn for this article was conducted as part of a bigger, ongoing study of recent social work and teacher graduates currently experiencing their first few years of professional employment in the Irish context. The group was mixed in terms of gender, age and ethnicity, although all participants were European in origin. All were qualified and practising social workers. The group members reported a spectrum of social media usage, ranging from a participant at one end of the spectrum who engaged in as many social media platforms as he could find to another participant who consciously avoided social media activity of any kind if possible. All participants were familiar with Facebook, LinkedIn and Twitter and because of this the discussion in general concentrated on these particular platforms, although the active social media user in the group offered additional insights into issues he had encountered on other social media sites also.

In terms of reputational issues, the group identified and discussed the public nature of social media sites, the lack of control by a person over the dissemination of information about them once it is posted, and their own observations of reputational damage related to social media usage.

In terms of the public nature of social media, the focus group participants reported personal experience of clients contacting them on Facebook or looking them up on Facebook during the active period of involvement by them as professionals with those clients. Examples were also given of Facebook friends turning up to their agency seeking a service and the potential blurring of professional boundaries this might cause. All agreed, and it had happened to one member of the group, that it would be advisable to share with their supervisor/team a situation where a Facebook friend became a client, so as to ensure that no future confusion about their management of their professional boundaries could arise. However, acknowledging the existence of an online friendship with a client, past, present or future, was only regarded as one step in a chain of decisions that flowed from such a situation. How to conduct oneself online with the client, both during and after the period of service delivery, led to debate within the group. Should online contact be suspended or terminated if a 'friend' became a client and if yes, how could that be done without causing offence or online damage to that person? Delisting a Facebook friend is a public action in an online environment, for example, and as well as causing offence it could lead to social consequences for that person.

All participants stated that they were forbidden under the terms of their employment to search online for information about their service users and any such activity on their part would therefore attract disciplinary action if they were found to have engaged in such behaviour. However, they also felt somewhat exposed to the possibility that clients could look them up online although the general consensus was that by being active 
online one had to be open to this kind of scrutiny and accept that it was something over which one has no actual control.

The lack of control over the dissemination of personal information, once it is posted online, was the main deterrent for some of the participants regarding active usage of social media sites. One person had experience of information being posted in an online environment which they were unhappy about and had tried to have certain aspects of their digital bio-history removed without success. This had caused distress and had strongly influenced that person's active avoidance of online communication.

A related issue raised by participants was the online behaviour of online friends which could be viewed by others as incompatible with their own professional identity and character. Some interviewees reported that this caused them to be aware of the potential relationship between online communication and professional reputational damage. Examples were provided of group Facebook pages, for example, a class of students, where someone in the group posted offensive remarks or comments which were regarded as incompatible with responsible professional and moral behaviour. Participants (more than one) gave examples of withdrawing from such group Facebook pages when their own moral compass signalled to them that the group behaviour threatened their professional reputation. Examples of this included disrespectful comments being posted about professional colleagues or professional events.

There was also a wide-ranging discussion about the overlap between private-life activity, details of which could be posted by self or others on social media sites, and the acceptable norms of professional conduct. All participants gave examples of people they knew, that is other professionals, posting photographs, videos or written reports of activities which, in the views of the participants, fell short of accepted professional codes of conduct. The issue for the participants was the 24/7 nature of professional reputation and how reputation could quickly be lost or compromised by any behaviour (in or outside work situations) which did not conform to the ethical standards of their profession. Examples provided included online reports, sometimes contemporaneous, of social situations involving alcohol or other substances. They reported, as a particular problem, being photographed during social events and those photographs appearing online on social media pages of other people, which were then viewed by clients, employers or members of the wider profession. The invasion of social media into their private domain, whether they were active media users or not, was reported as an issue of which they were increasingly aware and which was becoming problematic for many people in their wider professional network. Again, the difficulty in erasing such digital records was a major concern to the participants and their knowledge and skill in how to manage data deletion varied considerably.

A final issue, recurring throughout the data, is the varying levels of knowledge regarding both the technological aspects of managing online communication as well as the social implications of online activity, in particular, the professional implications. During the course of the focus-group discussion, the dialogue often reverted to straightforward information-sharing about how to manage settings on different social media sites, the tracking and sharing capabilities of various technologies, and even the basics of setting up different types of accounts, construction of avatars and management of information. The issue of professional reputation in an online world saw active engagement of all of the focus group participants in the discussion but at the same time revealed varying levels of prior consideration of the topic. While some had withdrawn active engagement on particular sites out of concern that their reputation could be compromised, all were concerned that, through either their own lack of knowledge or lack of awareness or that of colleagues, their professional reputation could be easily tarnished in online environments. The message from the group for educators was that students and early stage professionals need help and guidance to work their way through the various ethical dimensions of online communication before they do something which is difficult to reverse or retrieve.

\section{Discussion}

The day-to-day management of boundary issues between professionals and their clients, be they school children or adult clients, is an issue which affects all professions. Being active on social media platforms offers a new site for social interaction with friends, family and colleagues, but it also presents new opportunities for relationship-boundary problems to arise between professionals and their client populations. For example, the 
action of self-disclosure, so important for the development of online relationships (Sheldon, 2008), may present opportunities for professionals to unwittingly invade the privacy of their clients and vice versa.

The data from the focus-group interview with new social workers in Ireland revealed extensive use of asynchronous technologies by the research participants. Through the data, different perspectives emerged on the ethical component of online interaction, and its potential to interfere with, damage or possibly destroy the professional reputation which participants had worked so hard to acquire.

Although an increasing literature is emerging concerned with the ethical issues pertaining to online interaction, particularly for professionals (see for example, Teaching Council of Ireland, 2012), it appears that members of the 'always-on' generation (Belsey, 2004), fluent in their use of emerging technologies are less fluent in their awareness of the potential for online communication to interfere with their professional reputations. This may reflect the poor attention paid to online netiquette and e-professionalism across many professional education programmes (Kirwan, 2012). Research which can contribute to knowledge and education in this area, which can support the development of codes of online conduct for professionals and which can heighten awareness of the potential pitfalls, as well as the potential advantages, of online communication for professionals, is urgently necessary.

\section{Conclusions}

The data from the study of social media usage by new social workers and teachers suggest that netiquette awareness may not automatically flow from active netizenship (Bondolfi, 2013) and that professional groups themselves may need to take a leadership role in defining and supporting ethical online behaviour for individual members in much the same way as they have traditionally done in the off-line environment.

The results of this study will be of interest to professional educators but will be of particular interest to new graduates or possibly all professionals who engage in social media where they adopt a persona which may or may not be compatible with their off-line professional reputation and identity.

\section{References}

Belsey, B: Cyber-bullying: An emerging threat to the 'always on' generation. 2004. Retrieved September 12, 2009, from http://www.cyberbullying.ca/pdf/Cyberbullying Article by Bill Belsey.pdf

Bondolfi, T: Netizenship. Retrieved March 4, 2013, from: http://www.ynternet.org/ynternet.org

Cournoyer, Brian R.: The Social Work Skills Workbook. $5^{\text {th }}$ ed. Belmont, CA, Thomson Brooks/Cole. 2008

Eisenegger, Mark: Trust and Reputation in the Age of Globalisation' in Joachim Klewes and Robert Wreschniok (eds.) Reputation Capital: Building and Maintaining Trust in the $21^{\text {st }}$ Century. London, UK, Springer Verlag. 2009

Kirwan, Gloria: Social media, e-professionalism and netiquette in social work. Irish Social Worker, Autumn (2012): 9-12.

Krueger, R.A. and Casey, M.A.: Focus Groups. $4^{\text {th }}$ ed. London, United Kingdom, Sage Publications. 2009.

Sheldon, P.: The relationship between unwillingness to communicate and students' Facebook use. Journal of Media Psychology 20, (2008): 67-75.

The Teaching Council: Code of Professional Conduct for Teachers. $2^{\text {nd }}$ ed. Maynooth, Co. Kildare, Ireland, The Teaching Council. Available at http://www.teachingcouncil.ie/professional-standards/code-of-professional-conduct-for-teachers. 1425.html

Wilson, Kate, Ruch, Gillian, Lymbery, Mark, and Cooper, Andrew: Social Work. An introduction to contemporary practice. $2^{\text {nd }}$ ed. Essex, UK, Pearson Education Ltd. 2011. 